\title{
Anti-inflammatory effects of high-dose inhaled fluticasone versus oral prednisone in asthma exacerbations
}

\author{
J. Belda*, G. Margarit*, C. Martínez\#, J. Bellido-Casado*, P. Casan*, M. Torrejón*, \\ M. Brufal*, F. Rodríguez-Jerez* and J. Sanchis*
}

ABSTRACT: The objective of the present study was to investigate the kinetics of high doses of inhaled steroid fluticasone in comparison with oral steroid prednisone on plasma protein leakage and bronchial eosinophilia in adults with moderate asthma exacerbations.

The study design was a randomised, double-blind, placebo-controlled prospective trial. In total, 45 patients treated at the emergency department for moderate asthma exacerbations were recruited and 39 were assigned to receive fluticasone and placebo of prednisone (19 patients), or prednisone and placebo of fluticasone (20 patients). Medication was administered to all patients via a metered-dose inhaler and spacer (16 puffs; $4,000 \mu \mathrm{g} \cdot$ day $^{-1}$ or placebo) plus one pill (prednisone $30 \mathrm{mg} \cdot \mathrm{day}^{-1}$ or placebo). Spirometry and induced sputum for differential cell counts, albumin and $\alpha_{2}$-macroglobulin levels and blood eosinophils, interleukin-5 and granulocytemacrophage colony-stimulating factor levels were obtained before treatment and at 2, 6 and $24 \mathrm{~h}$ after treatment.

Symptoms clearly improved after $24 \mathrm{~h}$ in both groups. No differences were seen between groups in peak expiratory flow or forced expiratory flow in one second, which improved progressively but then decayed slightly after $24 \mathrm{~h}$. Eosinophil counts in sputum also improved over time in both groups. The effect was faster with fluticasone than with prednisone, but was partially lost at $24 \mathrm{~h}$. However, plasma proteins in sputum and eosinophil count in blood both decreased until $24 \mathrm{~h}$, with no significant differences between groups. There was no correlation between eosinophil counts and plasmatic protein levels.

In conclusion, both treatments improved symptoms, airway obstruction and inflammation, and plasma protein leakage at $24 \mathrm{~h}$. Prednisone reduced blood eosinophil counts, while fluticasone reduced airway eosinophil counts, suggesting that the anti-inflammatory performance of fluticasone is exerted locally.

KEYWORDS: Albumin, eosinophil, fluticasone, $\alpha_{2}$-macroglobulin, plasma exudation, prednisone, sputum induction

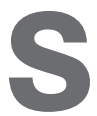
ystemic corticosteroids are currently recommended in acute asthma because they prevent the progression of exacerbations, decrease the hospitalisation rate and reduce morbidity [1]. Despite general agreement that systemic corticosteroids play an important role in acute asthma, there are significant doubts about short-term efficacy. RODRIGO and RODRIGO [2] and STEIN and COLE [3] have reported that i.v. parenteral corticosteroids have no bronchodilator effect within the first few hours of an acute asthma exacerbation. However, a systemic corticosteroid

For editorial comments see page 1035. effect does occur within the first 6-8 h after administration; this treatment probably requires a number of hours to effectively improve airflow obstruction, and some authors have questioned the efficacy of this treatment to control exacerbation during the first hours. The corticosteroid effect may be slow because these drugs require ligand-dependent activation of the corticosteroid receptor transcriptional factor [4].

Conversely, inhaled corticosteroids are recommended to control chronic asthma and reduce the need for oral prednisone [1, 5-7]. In acute asthma, they are only recommended for asthma treatment after emergency room discharge because they
AFFILIATIONS

*Departament de Pneumologia, Clínica d'Asma i Allèrgia, and " Servei de Bioquímica, Hospital de la Santa Creu i de Sant Pau, Facultat de Medicina, Universitat Autònoma de Barcelona, Barcelona, Spain.

CORRESPONDENCE

J. Belda

Servicio Neumología

Consorci Hospital General

Universitari de Valencia

Tres Creus 2

46014 Valencia

Spain

Fax: 34961972128

E-mail: belda_josram@gva.es

Received:

April 122006

Accepted after revision:

July 172007

SUPPORT STATEMENT

The study was supported in part by Red Respira (RITC-ISCIII)-Spanish

Society of Pneumology (SEPAR).

STATEMENT OF INTEREST

None declared.

European Respiratory Journal Print ISSN 0903-1936 Online ISSN 1399-3003 
reduce the chance of worsening after such attacks [8]. Other authors have suggested that high-dose inhaled corticosteroids in emergency rooms would act faster than oral or parenteral corticosteroids [9-14]. Confirmation of these data would necessitate important modifications in today's guidelines for acute asthma [15]. Additionally, some safety concerns have arisen because no data are available about the mechanism by which inhaled steroids could have a faster effect than systemic corticosteroids. In the previously mentioned editorial, MCFADDEN [15] suggested that inhaled steroids would reduce oedema and plasma exudation quicker than oral steroids. However, a more complex mechanism cannot be discarded because early changes (within 2-3 h) in cellular and biochemical markers of bronchial inflammation have been described after systemic [16] and inhaled corticosteroid treatment [17, 18] in uncontrolled asthmatics.

The present randomised clinical trial was performed to study the mechanism through which inhaled steroids could act faster than oral steroids in acute asthma. The aim was to compare the effect of high doses of inhaled fluticasone with oral prednisone on airway plasma protein exudation. Relative indices of albumin and $\alpha_{2}$-macroglobulin were calculated through the ratio between sputum and blood. Furthermore, the antiinflammatory effects were assessed by the sputum eosinophil counts and the concentration of interleukin (IL)-5 and granulocyte-macrophage colony-stimulating factor (GM-CSF) in peripheral blood.

\section{MATERIAL AND METHODS \\ Subjects}

All participants were recruited consecutively from patients with acute asthma at the Emergency Department, Hospital de la Santa Creu i de Sant Pau, Barcelona, Spain. The present study conforms to the Helsinki Declaration and was approved by the hospital's Ethics and Clinical Assays Committee. All participants gave written informed consent to participate in the study. Inclusion criteria were as follows. 1) Patients had acute asthma and were aged between 16-65 yrs with no oral or i.v. steroid treatment in the last 4 weeks. 2) All had been diagnosed with asthma from current or previous history of chest tightness, wheezing, dyspnoea or cough in association with variable airflow limitation. 3) Variable airflow limitation was documented from either methacholine airway hyperresponsiveness (provocative concentration causing a $20 \%$ fall in forced expiratory volume in one second (FEV1) $<8 \mathrm{mg} \cdot \mathrm{mL}^{-1}$ ) if FEV1 was $\geqslant 70 \%$ of predicted value, or $12 \%$ increases in FEV1 after inhaled salbutamol $200 \mu \mathrm{g}$ if FEV1 was $<70 \%$. 4) The exacerbation was considered moderate to severe, but not life threatening at baseline, strictly in accordance with the Global Initiative for Asthma criteria [1].

Exclusion criteria included the following: 1) smokers or exsmokers within the last year; and 2) treatment with oral or i.v. corticosteroids, cromoglycate, nedocromil, theophylline, allergen-desensitisation injections, and leukotriene antagonists at any time in the 4 weeks prior to the study. Long-acting $\beta$ agonists were permitted, but participants on this treatment were balanced between the two groups (block randomisation). Subjects with life-threatening exacerbations of asthma at baseline or any other serious medical conditions were excluded, e.g. heart disease, gastro-intestinal, liver or renal disease, or other chest disease which could interfere with the study outcome, as judged by the investigators.

\section{Design and methods}

A sequential, placebo-controlled, double-blind, clinical trial was designed comparing oral prednisone and inhaled fluticasone. Baseline measurements were recorded at admission. Severity of exacerbation was assessed from clinical history, physical examination, peak expiratory flow (PEF) measurement and oxyhaemoglobin saturation. Additionally, peripheral blood and sputum were collected. After initial treatment with nebulised salbutamol ( $1 \mathrm{~mL}$ in $3 \mathrm{~mL}$ of isotonic saline for 15 min with a Hudson jet nebuliser) and oxygen, patients were re-evaluated as either suitable or unsuitable for the study. They were then randomly treated with either a $30 \mathrm{mg} \cdot \mathrm{day}^{-1}$ prednisone tablet plus 16 inhalations of fluticasone-like placebo, or a prednisone-like placebo tablet plus 16 inhalations $\left(4,000 \mu \mathrm{g} \cdot\right.$ day $\left.^{-1}\right)$ of fluticasone $250 \mu \mathrm{g}$.

Patients' allocation to treatment one or two was concealed by following computerised randomisation, codified by the hospital's Pharmacy Dept, who also packed and blinded all medications. Fluticasone and its placebo were kindly donated by GlaxoSmithKline (Madrid, Spain). Prednisone and its placebo were obtained from common sources. The appearance, taste and texture of the prednisone and placebo and fluticasone and placebo were similar, so the two were indistinguishable.

Each treatment was given in a single dose under supervision at baseline and at $24 \mathrm{~h}$, as of which time patients were instructed to continue taking one tablet each morning and eight inhalations twice a day for 4 days. Measurements were made at baseline and at 2, 6 and $24 \mathrm{~h}$. At each proposed time, asthma symptoms (cough, wheeze, chest tightness and breathlessness) were recorded. Measurements were performed in the following order: 1) symptoms score; 2) PEF; 3) peripheral blood withdrawal; and 4) sputum collection. The laboratory was blinded to clinical details during sputum and blood measurements. Inhaled medication was administered through a spacer camera according to the manufacturer's instructions and was always supervised by investigators. The following safety protocol was applied: participants were followed in the respiratory day-care setting for $6 \mathrm{~h}$ and then discharged if symptoms improved and PEF increased by $\geqslant 30 \%$ above baseline value. If the patients did not improve, they were kept in observation for $24 \mathrm{~h}$. During observation, it had been previously established that patients would be shifted to the other arm in case of worsening (decrease of PEF $>20 \%$ of baseline or clinical deterioration judged by the responsible physician). No other treatments were allowed other than nebulised salbutamol every $4 \mathrm{~h}$ and oxygen on demand. For safety reasons, patients were visited at 1 and 3 weeks after exacerbation. They were asked about treatment compliance and their home diary, in which their recorded PEF and symptoms were reviewed.

\section{Procedures}

Patient characteristics and physical examination

Sex, age, history of smoking habits, allergen injection treatment, possible relevant allergen exposure or trigger of asthma exacerbation, symptoms of asthma and medications were recorded in a closed questionnaire. Physical examination was 
performed, including measurement of oxyhaemoglobin saturation. Symptom severity was recorded on a four-point scale $(0$ : not at all; 1: mild, but I can continue my work; 2: moderate intensity, I need to stop at least for a while; and 3: severe intensity, I cannot continue my work).

\section{PEF technique}

Patients were instructed and checked for adequate PEF technique following Global Initiative of Asthma recommendations [1].

\section{Spirometry}

Spirometry was performed with a Datospir 500 (Sibelmed S.A., Barcelona, Spain) according to the procedure and predicting values described by the European Respiratory Society [19].

\section{Sputum induction and processing}

Sputum was obtained $10 \mathrm{~min}$ after salbutamol nebulisation. Subjects were asked to blow their nose, rinse their mouth and swallow the water to minimise contamination with post-nasal drip and saliva. They were then asked to cough sputum into a sterile container. The specimen was put in the refrigerator $\left(4^{\circ} \mathrm{C}\right)$ and processed as soon as possible, as described by PIZZICHINI et al. [20]. Total cell count was obtained in a modified Neubauer haemocytometer. The cell viability was determined by the trypan blue exclusion method. The total and absolute number of cells per milligram of processed sputum was calculated. In total, 400 nonsquamous cells were counted in Wright-stained slides and the results expressed as a percentage and absolute number of the total nonsquamous count.

\section{Serum and sputum protein measurements}

Albumin in sputum $\left(\mathrm{mg} \cdot \mathrm{L}^{-1}\right)$ was measured by an immunoturbidimetric assay (Albumina Tina-quant (C) Ref 11875400; Roche/Hitachi, Roche Diagnostics GmbH, Mannheim, Germany) and in serum $\left(\mathrm{g} \cdot \mathrm{L}^{-1}\right)$ by a colourimetric assay (ALB plus Ref 1929640; Roche Diagnostics GmbH, Mannheim, Germany). $\alpha_{2}$-Macroglobulin in sputum $\left(\mathrm{mg} \cdot \mathrm{L}^{-1}\right)$ and serum $\left(\mathrm{g} \cdot \mathrm{L}^{-1}\right)$ was measured by a nephelometric method $\left(\alpha_{2}\right.$-macroglobulin antiserum, Ref SAM/15; Dade Behring, Marburg, Germany). The results were adjusted for the dilution applied (four times) and expressed as relative coefficient, calculated as sputum level divided by serum level.

\section{White cell and IL blood measurements}

Peripheral venous blood $(20 \mathrm{~mL})$ was drawn into adequate tubes from each subject. A white differential cell count on whole blood using automated counter was performed. IL-5 and GM-CSF were measured by doubled-sandwich ELISA.

\section{Statistical analysis}

In terms of sample size calculations, the present authors aimed to recruit 18-20 patients with moderate-to-severe asthma exacerbations for each arm of the study. These numbers would be sufficient with respect to the primary outcome if there were an $\alpha$ specification of 0.05 , a $\beta$ specification of 0.2 and at least a $50 \%$ difference between the two treatment groups, as described in a previous study [21]. The primary outcome was the relative indices of albumin and $\alpha_{2}$-globulin.

Results were expressed as arithmetic mean \pm SD or median (interquartile range), depending on their distribution.
Repeated-measures ANOVA was used to analyse the effect of time as a within-subject factor and the effect of treatment as the between-subject factor in the model. Dependent variables were PEF, percentage of eosinophils and the relative indices of albumin and $\alpha_{2}$-globulin. Previous inhaled treatment was used as covariant. The factors were as follows: 1) within-subjects factor "effect of time" (baseline and 2, 6 and 24 h); and 2) between-subjects factors "effect of treatment" (prednisone, fluticasone). As there were some differences between groups at baseline (although the differences were nonsignificant), the analyses were repeated, adjusting by the baseline data as covariant. The level of significance was $95 \%$.

\section{RESULTS}

Four induced sputum samples suitable for processing were obtained in 39 out of the 45 participants. In total, 20 patients were randomised to the prednisone group and 19 to the fluticasone group. Four cases were excluded because the sputum samples were not suitable for processing (two from each group). Two further cases were excluded because of chest radiograph infiltrates compatible with pneumonia. Table 1 describes anthropometric, spirometry and cytological characteristics of both groups. In total, 24 subjects were receiving previous regular treatment with inhaled steroids, 15 on budesonide (five in the prednisone and 10 in the fluticasone group) and nine on fluticasone (five in the prednisone and four in the fluticasone group). The other 15 cases did not receive regular inhaled steroids (10 in the prednisone and five in the fluticasone group). The trigger was identified as upper airways infection in $\sim 50 \%$ of the cases (10 in the prednisone group and nine in the fluticasone group). Other triggers seemed to be due either to allergen exposure or reasons were unidentified. The acute exacerbation started on the same day in only three cases. The majority had had symptoms for $\geqslant 2$ days before admission. There was no significant difference at baseline between groups, particularly regarding the eosinophil counts (prednisone group mean \pm SD $18 \pm 24 \%$ and fluticasone group $13 \pm 20 \%$ ), the relative index of albumin (mean \pm SD $273 \pm 214 / 43 \pm 3$ and $480 \pm 494 / 43 \pm 3$, respectively) or $\alpha_{2}$ macroglobulin (mean \pm SD $6 \pm 6 / 2 \pm 1$ and $17 \pm 23 / 2 \pm 1$, respectively). However, additional analysis adjusting by baseline values was performed because data between groups differed.

\section{Effect of treatment on symptoms and airflow limitation}

The symptom score, mainly in relation to physical activity, showed that both groups started with moderate-to-severe dyspnoea and improved $24 \mathrm{~h}$ later (table 2). However, there were no significant differences between groups $(\mathrm{F}=0.59$, $\mathrm{p}=0.44$; fig. 1).

Airway obstruction was similar between groups at baseline in PEF and FEV1 (table 2), improving progressively during the first $6 \mathrm{~h}$ and decaying slightly after $24 \mathrm{~h}$. There were no significant differences between treatment groups $(\mathrm{F}=0.03$, $\mathrm{p}=0.89$ for PEF (fig. 2); or $\mathrm{F}=0.1 .02, \mathrm{p}=0.32$ for $\mathrm{FEV} 1$ (fig. 3)).

Effect of treatment on sputum and blood eosinophil counts In sputum, the prednisone group started with higher eosinophil counts, although the difference was not statistically significant. Both groups then improved eosinophil counts over time, but decreased more rapidly and more strongly in the fluticasone group $(\mathrm{F}=4.27, \mathrm{p}=0.036$ after adjusting by baseline 


\begin{tabular}{|c|c|c|c|}
\hline $\begin{array}{l}\text { Antl } \\
\text { cha }\end{array}$ & $\begin{array}{l}\text { ropometric, } s p \\
\text { acteristics of } p\end{array}$ & $\begin{array}{l}\text { ometry and cy } \\
\text { tients in both }\end{array}$ & $\begin{array}{l}\text { logical } \\
\text { oups }\end{array}$ \\
\hline & Prednisone & Fluticasone & p-value \\
\hline Subjects n & 20 & 19 & \\
\hline Males n & 7 & 4 & \\
\hline Age yrs & 34 (19-68) & $39(20-69)$ & 0.46 \\
\hline IC $\mu \mathrm{g} \cdot$ day $^{-1}$ & $10(502 \pm 740)$ & $5(568 \pm 553)$ & 0.28 \\
\hline Symptom score & $2.6 \pm 0.7$ & $2.5 \pm 0.8$ & 0.57 \\
\hline PEF L· $\min ^{-1}$ & $289 \pm 99$ & $315 \pm 98$ & 0.44 and 0.07 \\
\hline PEF \% & $54 \pm 15$ & $63 \pm 16$ & \\
\hline FEV1 L & $2.09 \pm 0.98$ & $2.11 \pm 0.74$ & 0.45 and 0.11 \\
\hline FEV $1 \%$ & $62 \pm 20$ & $69 \pm 19$ & \\
\hline Eosinophils \% & $18 \pm 24$ & $13 \pm 20$ & 0.83 \\
\hline Neutrophils \% & $49 \pm 29$ & $56 \pm 36$ & 0.67 \\
\hline Macrophages \% & $28 \pm 19$ & $28 \pm 27$ & 0.59 \\
\hline Lymphocytes \% & $2 \pm 2$ & $2 \pm 2$ & 0.51 \\
\hline Albumin sp/blood & $273 \pm 214 / 43 \pm 3$ & $480 \pm 494 / 43 \pm 3$ & 0.45 \\
\hline$\alpha_{2}$-Macro sp/blood & $6 \pm 6 / 2 \pm 1$ & $17 \pm 23 / 2 \pm 1$ & 0.67 \\
\hline
\end{tabular}

Data are presented as $n$ (range), $n$ (mean $\pm S D$ ) or mean $\pm S D$, unless otherwise stated. IC: previous treatment with inhaled corticosteroids and mean dose $\cdot$ day $^{-1}$ received; PEF: peak expiratory flow; FEV1: forced expiratory volume in one

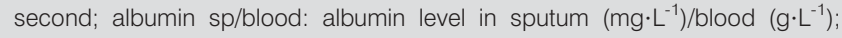
$\alpha_{2}$-macro sp/blood: $\alpha_{2}$-macroglobulin in sputum $\left(\mathrm{mg} \cdot \mathrm{L}^{-1}\right) /$ blood $\left(\mathrm{g} \cdot \mathrm{L}^{-1}\right)$

values) than in the prednisone group. This effect, however, was partially lost at $24 \mathrm{~h}$ from baseline (fig. 4).

In contrast, prednisone reduced blood eosinophil counts more strongly than fluticasone, although no more rapidly $(\mathrm{F}=11.862$, $p=0.0001$ after adjusting by baseline values; fig. 5).

\section{Effect of treatment on plasmatic protein relative indices}

Relative indices of plasmatic proteins decreased progressively during the first $24 \mathrm{~h}$ with a slight recovery at $24 \mathrm{~h}$. There were no significant differences between treatment groups $(\mathrm{F}=0.27$, $\mathrm{p}=0.60$ for albumin (fig. 6) and $\mathrm{F}=0.16, \mathrm{p}=0.70$ for $\alpha_{2^{-}}$ macroglobulin, respectively).

\section{Effect of treatment on blood IL levels}

The effect of treatment on blood IL-5 and GM-CSF levels was measured, but many determinations $(>50 \%)$ could not be

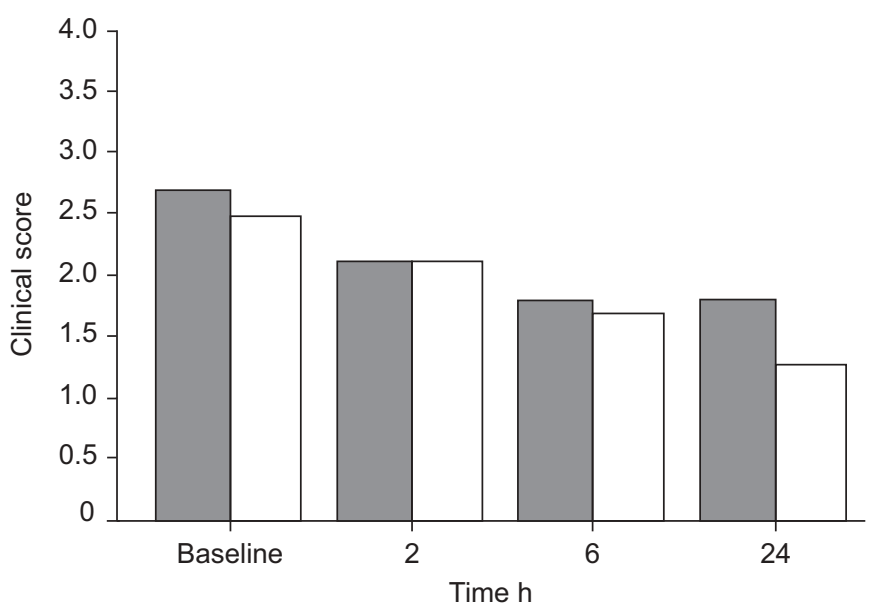

FIGURE 1. Symptom score at baseline and at 2, 6 and $24 \mathrm{~h}$ for the prednisone group ( $\square$ ) and fluticasone group ( $\square$ )

analysed because they were below the detection levels of the technique.

\section{Relationship between protein levels and sputum cells}

There was no significant correlation between eosinophil counts and albumin or $\alpha_{2}$-macroglobulin $(\mathrm{r}=0.11, \mathrm{p}=0.54$ and $\mathrm{r}=0.25$, $\mathrm{p}=0.17$, respectively), but there was a significant correlation between albumin or $\alpha_{2}$-macroglubulin levels and neutrophil counts $(r=0.62, p=0.001$ and $r=0.58, p=0.001$, respectively).

\section{DISCUSSION}

In the present study, high doses of the inhaled fluticasone were at least as effective as oral prednisone in the treatment of moderate asthma attacks. At $24 \mathrm{~h}$, both treatments improved symptoms, bronchoconstriction, eosinophilic bronchitis and plasma protein leakage. However, fluticasone showed a tendency to act faster than prednisone on bronchoconstriction and plasma protein leakage, although its main effect was the reduction of sputum eosinophilia, which was significant as early as $2 \mathrm{~h}$ after inhalation, reaching a maximum at $6 \mathrm{~h}$. Prednisone also reduced sputum eosinophilia, but with effects being noticeable at a mean of $6 \mathrm{~h}$ after administration, and the decrease was weaker than that of fluticasone. Conversely, prednisone showed a stronger and statistically significant reduction in blood eosinophilia as compared with fluticasone.

TABLE 2 Absolute values obtained by times and treatment groups

\begin{tabular}{|c|c|c|c|c|c|c|c|c|}
\hline & \multicolumn{4}{|c|}{ Prednisone } & \multicolumn{4}{|c|}{ Fluticasone } \\
\hline & Baseline & $2 \mathrm{~h}$ & $6 \mathrm{~h}$ & $24 \mathrm{~h}$ & Baseline & $2 \mathrm{~h}$ & $6 \mathrm{~h}$ & $24 \mathrm{~h}$ \\
\hline Symptom score & $2.68 \pm 0.75$ & $2.11 \pm 1.15$ & $1.79 \pm 1.08$ & $1.79 \pm 1.03$ & $2.47 \pm 0.84$ & $2.11 \pm 0.81$ & $1.68 \pm 1.00$ & $1.26 \pm 1.10$ \\
\hline PEF L. $\mathrm{min}^{-1}$ & $289 \pm 99$ & $351 \pm 91$ & $371 \pm 108$ & $319 \pm 121$ & $315 \pm 98$ & $361 \pm 108$ & $347 \pm 112$ & $332 \pm 114$ \\
\hline FEV 1 \% r.v. & $61.6 \pm 19.8$ & $71.9 \pm 18.9$ & $74.0 \pm 18.7$ & $64.7 \pm 21.5$ & $69.1 \pm 18.8$ & $78.9 \pm 20.1$ & $76.8 \pm 20.6$ & $71.6 \pm 20.1$ \\
\hline Eosinophils \% & $18.2 \pm 23.8$ & $16.6 \pm 20.7$ & $12.2 \pm 15.7$ & $13.0 \pm 17.2$ & $13.3 \pm 19.8$ & $7.3 \pm 8.4$ & $4.8 \pm 7.6$ & $6.4 \pm 14.0$ \\
\hline Albumin ${ }^{\#} \mathrm{mg} \cdot \mathrm{L}^{-1}$ & $273 \pm 214$ & $298 \pm 238$ & $229 \pm 249$ & $263 \pm 302$ & $480 \pm 494$ & $302 \pm 258$ & $268 \pm 255$ & $294 \pm 324$ \\
\hline$\alpha_{2}-$ Macroglobulin ${ }^{\#} \mathrm{mg} \cdot \mathrm{L}^{-1}$ & $5.8 \pm 6.1$ & $9.0 \pm 10.1$ & $7.3 \pm 8.1$ & $7.3 \pm 12.2$ & $17.5 \pm 23.4$ & $11.5 \pm 9.5$ & $11.3 \pm 12.9$ & $16.4 \pm 24.0$ \\
\hline
\end{tabular}

Data are presented as mean \pm SD. PEF: peak expiratory flow; FEV1: forced expiratory volume in one second; \% r.v.: \% of reference value. ${ }^{\#}$ : level in sputum. 


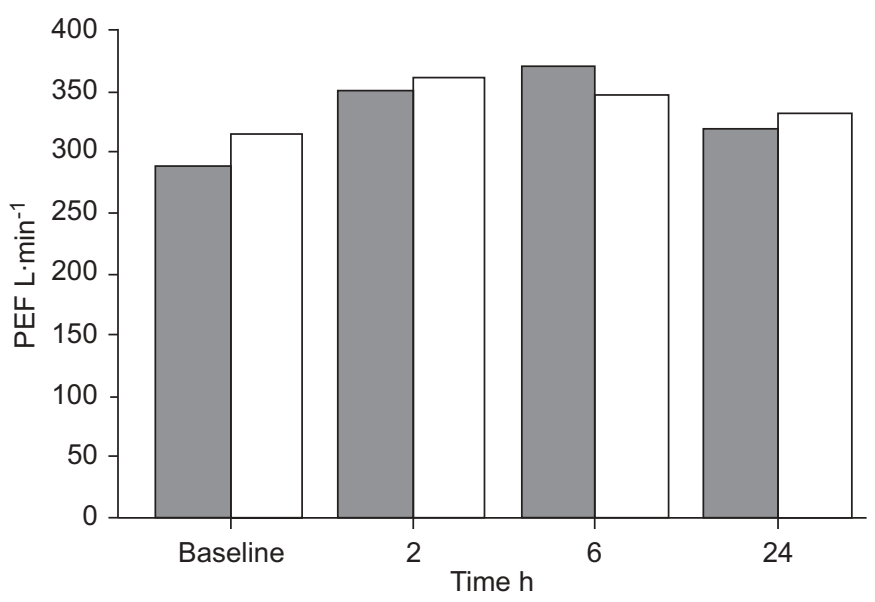

FIGURE 2. Peak expiratory flow (PEF) at baseline and at 2,6 and $24 \mathrm{~h}$ for the prednisone group ( $\square$ ) and fluticasone group ( $\square$ )

The usefulness of inhaled steroids in the emergency room is unclear. The recent Cochrane review of this topic [22] stated that inhaled steroids reduce readmission rates in patients with acute asthma. Nevertheless, it is unclear whether inhaled corticosteroids used in addition to systemic corticosteroids provide any benefit. The Cochrane review [22] did not find sufficient evidence that inhaled corticosteroids provide clinically relevant changes in pulmonary function or clinical scores in acute asthma. Moreover, there is insufficient evidence that inhaled corticosteroids alone are as effective as systemic steroids. Further research was thus recommended to clarify this point. Some authors have suggested that inhaled steroids seem to act faster than oral steroids on symptoms and airway obstruction [9-14], although there is considerable controversy on this point in children $[23,24]$. In the present study, both prednisone and high doses of fluticasone reduced airway obstruction and improved symptoms. Notwithstanding, the present study was not designed to answer this question and sufficient statistical power was not found to confirm this point. The present results, however, clearly showed that both

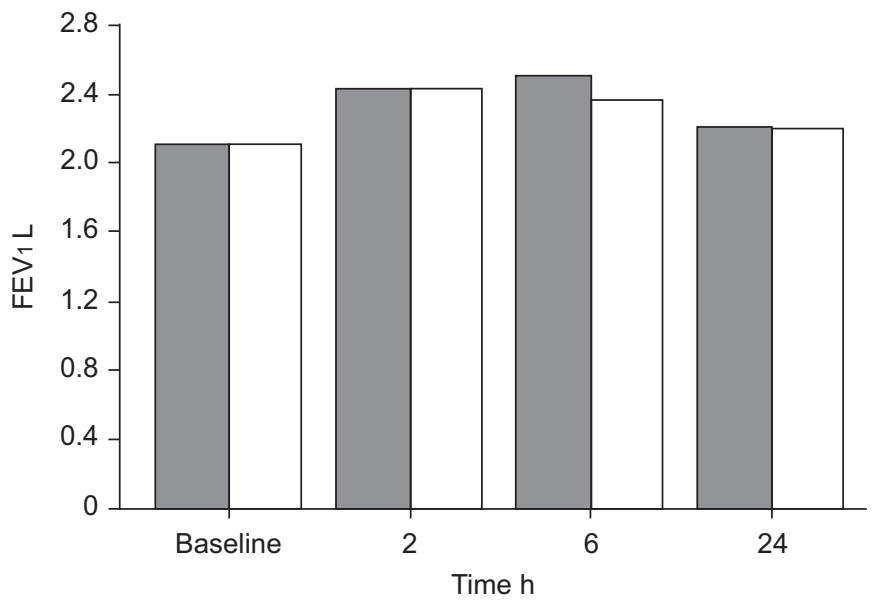

FIGURE 3. Estimated adjusted values of forced expiratory volume in one second (FEV 1 ) at baseline and at 2, 6 and $24 \mathrm{~h}$ for the prednisone group ( $\square$ ) and fluticasone group ( $\square$ ).

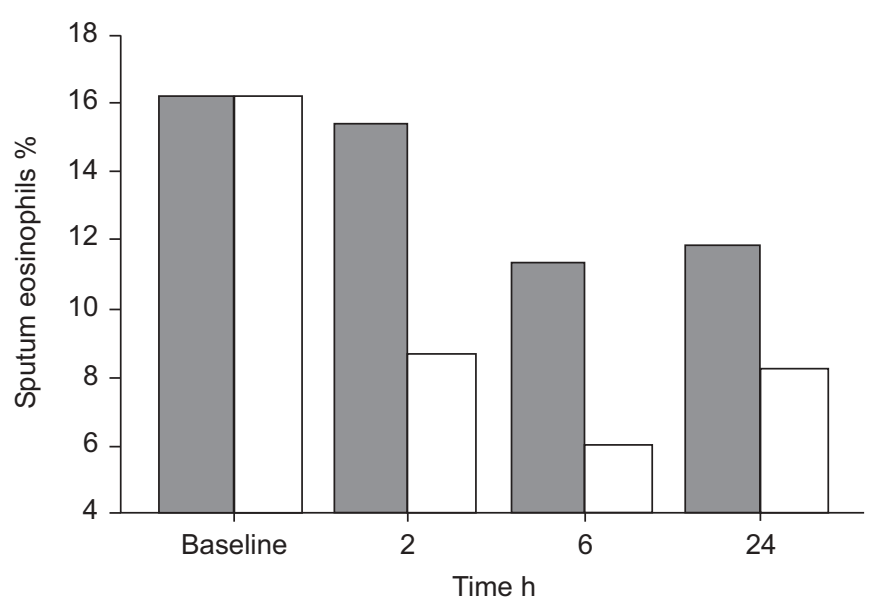

FIGURE 4. Estimated adjusted values of sputum eosinophil counts at baseline and at 2, 6 and $24 \mathrm{~h}$ for the prednisone group ( $\square$ ) and fluticasone group ( $\square$ ).

treatments reduced airway inflammation and plasma protein exudation, although in a different way.

In patients with stable asthma, many authors have established that there is an increased plasma exudation in the airways. This correlates with bronchial hyperreactivity to histamine and decreases after corticosteroid therapy. A few other groups have investigated protein plasma leakage during asthma exacerbation [25-27] and have shown that albumin leakage is highly increased as compared with that in stable asthmatics. To the present authors' knowledge, the present study is the first to demonstrate the efficacy of oral and inhaled steroid treatments in improving plasma protein leakage within the first $24 \mathrm{~h}$ of asthma exacerbation. Pizzichini et al. [28] showed that oral steroids in severe exacerbations of asthma decreased fibrinogen levels at day 7 . In the present study, oral, but also inhaled, steroids began to decrease albumin and $\alpha_{2}$-macroglobulin as early as $2 \mathrm{~h}$ after treatment. The reason for this discrepancy could lie in the different plasma proteins tested in each study, but whatever the case, the clinical relevance of this plasma leakage in the asthma exacerbation remains unknown. In a

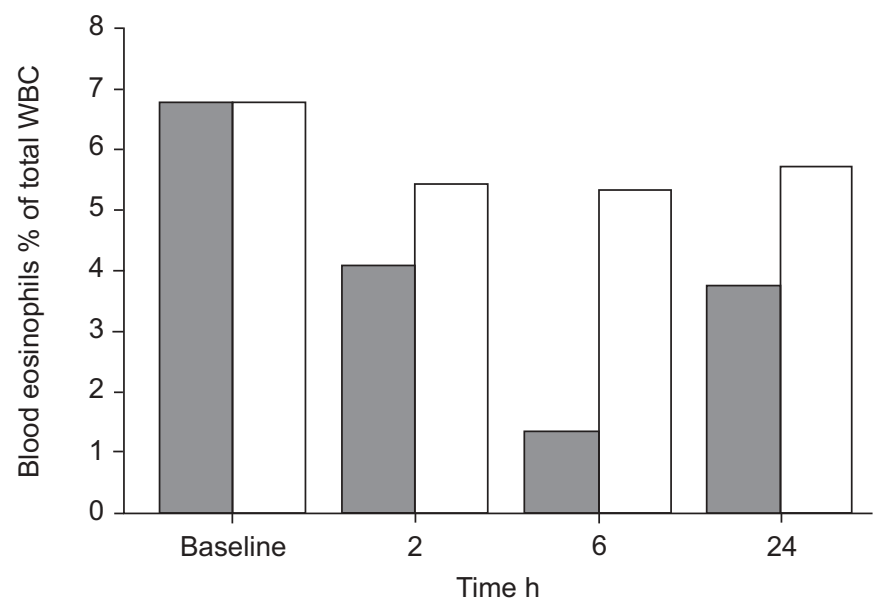

FIGURE 5. Blood eosinophil counts of white blood cells (WBC) at baseline and at 2, 6 and $24 \mathrm{~h}$ for the prednisone group ( $\square$ ) and fluticasone group ( $\square$ ). 


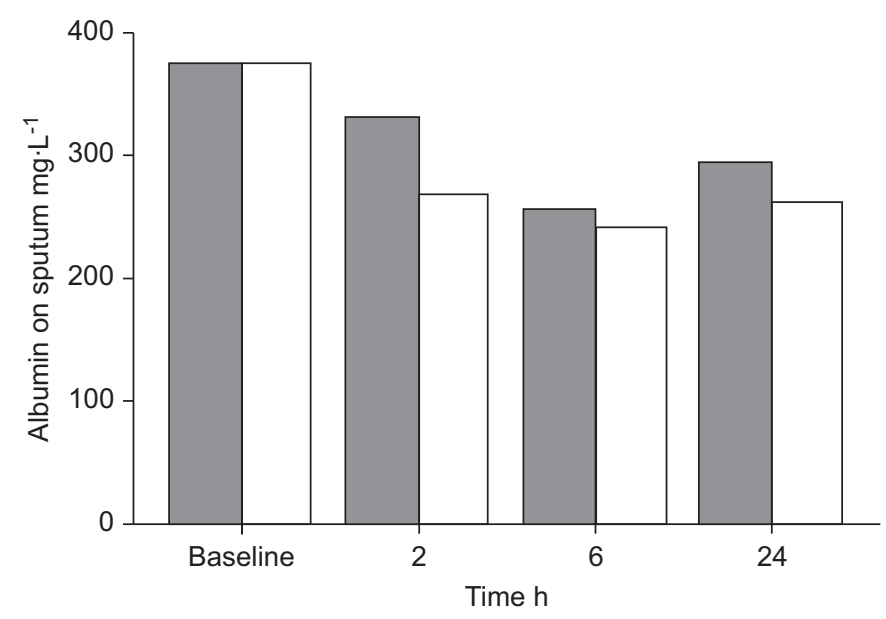

FIGURE 6. Estimated adjusted levels of albumin in sputum at baseline and at 2, 6 and $24 \mathrm{~h}$ for the prednisone group ( $\square$ ) and fluticasone group ( $\square$ ).

previous study [21], the present authors found that plasma leakage in acute asthma was weakly related to the degree of airway obstruction, suggesting that this effect may not account for the final severity of the exacerbation. Despite the fact that some relationship clearly exists, the importance of this finding should be further determined, since in the current study, a significant relationship between FEV1 and the relative index of albumin in the acute phase was found.

Many studies have shown a rapid, strong effect of inhaled steroids on bronchial eosinophilic inflammation, but such studies were generally performed on subjects with stable asthma or induced exacerbations. Very few data are available on naturally occurring exacerbations, probably because of the difficulty in obtaining bronchial secretions in the acute phase. The main outcome measure studied by many groups is, therefore, the improvement in airway obstruction [2], which is not a direct inflammatory marker. Data concerning the effect of inhaled steroids on sputum eosinophilia are not available in acute asthma. However, exacerbations induced by stepping down the inhaled corticosteroid therapy confirm this evidence and it can be assumed that corticosteroids should reduce blood and sputum eosinophilia in acute asthma. At least three studies [28-30] have reported that sputum eosinophilia improved after treatment with oral steroids. PIZZiCHINI et al. [28] described an improvement in sputum eosinophilia and eosinophil cationic protein levels at $24 \mathrm{~h}$. This was supported by the present authors' findings.

If inhaled steroids can act faster than systemic steroids, as suggested from the present results, the question is how this occurs. McFADDEN [15] suggested that inhaled steroids may improve exacerbations faster by reducing bronchial oedema. The present data do not support this possibility because both treatments improved plasma leakage in a similar way. The explanation suggested from the present findings is a faster anti-inflammatory effect of inhaled steroids, probably due to a reduction in bronchial eosinophil survival.

The main limitation of the present study is probably related to the high dose of fluticasone used, which is possibly not comparable with the doses used by others. In a very recent paper, RODRIGO [14] used 3,000 $\mu \mathrm{g} \cdot \mathrm{h}^{-1}$ during $3 \mathrm{~h}$ with excellent results. However, the dose used in the present study $\left(4,000 \mu \mathrm{g} \cdot \mathrm{day}^{-1}\right)$ is twice the fluticasone dose accepted for self-treatment of asthma attacks according to some guidelines [31]. Differences in the dose used may be important, because published studies that obtained better results [8, 10, 12-14] tended to use higher doses of inhaled steroids and lower oral steroid doses than those studies that found no benefits [11, 24, 32]. Therefore, it could be speculated that the dose of inhaled steroids needed to provide a benefit in acute asthma should be considerably higher than that used in stable asthma. The timing of the steroid administration may also be relevant. The present authors observed that the effect of both treatments was partially lost at $24 \mathrm{~h}$, suggesting that treatment should perhaps be administered twice daily to maintain efficacy.

In conclusion, high-dose inhaled fluticasone appears to have a faster and stronger effect in reducing airway inflammation than oral prednisone and to be at least as effective as prednisone in reducing plasma exudation, bronchial obstruction and symptoms in moderate exacerbations of asthma. The early combination of inhaled steroid to oral prednisone could therefore be more effective than prednisone alone in acute asthma. Further studies are needed to investigate whether lower doses of inhaled fluticasone are as effective as the $4,000 \mu \mathrm{g} \cdot$ day $^{-1}$ dose, as well as the comparison of this association versus oral prednisone alone.

\section{REFERENCES}

1 National Heart, Lung and Blood Institute/World Health Organization. Global Initiative for Asthma. Global Strategy for Asthma Management and Prevention. National Institutes of Health. Publication No. 02-3659. Bethesda, National Heart, Lung, and Blood Institute; 2002.

2 Rodrigo G, Rodrigo C. Corticosteroids in the emergency department therapy of acute adult asthma: an evidencebased evaluation. Chest 1999; 116: 285-295.

3 Stein LM, Cole RP. Early administration of corticosteroids in emergency room treatment of acute asthma. Thorax 1992; 47: 588-591.

4 Barnes PJ, Pedersen S, Busse WW. Efficacy and safety of inhaled corticosteroids. New developments. Am J Respir Crit Care Med 1998; 157: Suppl. 3, S1-S53.

5 Edmonds ML, Camargo CA Jr, Pollack CV Jr, et al. Early use of inhaled corticosteroids in the emergency department treatment of acute asthma. Cochrane Database Syst Rev 2003; 3: CD002308.

6 Rowe $\mathrm{BH}$, Edmonds ML, Spooner $\mathrm{CH}$, et al. Corticosteroid therapy for acute asthma. Respir Med 2004; 98: 275-284.

7 Harrison TW, Oborne J, Newton S, et al. Doubling the dose of inhaled corticosteroid to prevent asthma exacerbations: randomised controlled trial. Lancet 2004; 363: 271-275.

8 Edmonds ML, Camargo CA, Saunders LD, et al. Inhaled steroids in acute asthma following emergency department discharge. Cochrane Database Syst Rev 2000; 3: CD002316.

9 Rodrigo G, Rodrigo C. Inhaled flunisolide for acute severe asthma. Am J Respir Crit Care Med 1998; 157: 698-703.

10 Rodrigo GJ, Rodrigo C. Triple inhaled drug protocol for the treatment of acute severe asthma. Chest 2003; 123: 1908-1915. 
11 Lee-Wong M, Dayrit FM, Kohli AR, et al. Comparison of high-dose inhaled flunisolide to systemic corticosteroids in severe adult asthma. Chest 2002; 122: 1208-1213.

12 Guttman A, Afilalo M, Colacone A, et al. The effects of combined intravenous and inhaled steroids (beclomethasone dipropionate) for the emergency treatment of acute asthma. The Asthma ED Study Group. Acad Emerg Med 1997; 4: 100-106.

13 Levy ML, Stevenson C, Maslen T. Comparison of short courses of oral prednisolone and fluticasone propionate in the treatment of adults with acute exacerbations of asthma in primary care. Thorax 1996; 51: 1087-1092.

14 Rodrigo GJ. Comparison of inhaled fluticasone with intravenous hydrocortisone in the treatment of adult acute asthma. Am J Respir Crit Care Med 2005; 171: 1231-1236.

15 McFadden ER Jr. Inhaled glucocorticoids and acute asthma: therapeutic breakthrough or nonspecific effect? Am J Respir Crit Care Med 1998; 157: 677-678.

16 Hill MR, Szefler SJ, Ball BD, et al. Monitoring glucocorticoid therapy: a pharmacokinetic approach. Clin Pharmacol Ther 1990; 48: 390-398.

17 Laitinen LA, Laitinen A, Heino M, et al. Eosinophilic airway inflammation during exacerbation of asthma and its treatment with inhaled corticosteroid. Am Rev Respir Dis 1991; 143: 423-427.

18 Oh JW, Lee HB, Kim CR, et al. Analysis of induced sputum to examine the effects of inhaled corticosteroid on airway inflammation in children with asthma. Ann Allergy Asthma Immunol 1999; 82: 491-496.

19 Quanjer PH, Tammeling GJ, Cotes JE, Pederson OF, Peslin R, Yernault JC. Lung volumes and forced ventilatory flows. Report Working Party Standardization of Lung Function Tests, European Community for Steel and Coal. Official Statement of the European Respiratory Society. Eur Respir J 1993; 6: Suppl. 16, 5-40.

20 Pizzichini E, Pizzichini MM, Efthimiadis A, et al. Indices of airway inflammation in induced sputum: reproducibility and validity of cell and fluid-phase measurements. Am J Respir Crit Care Med 1996; 154: 308-317.

21 Belda J, Margarit G, Martínez C, et al. Bronchial exudate of serum proteins during asthma attacks. Arch Bronconeumol 2005; 41: 328-333.
22 Edmonds ML, Camargo CA Jr, Pollack CV Jr, et al. Early use of inhaled corticosteroids in the emergency department treatment of acute asthma. Cochrane Database Syst Rev 2003; 3: CD002308.

23 Nakanishi AK, Klasner AK, Rubin BK. A randomized controlled trial of inhaled flunisolide in the management of acute asthma in children. Chest 2003; 124: 790-794.

24 Afilalo M, Guttman A, Colacone A, et al. Efficacy of inhaled steroids (beclomethasone dipropionate) for treatment of mild to moderately severe asthma in the emergency department: a randomized clinical trial. Ann Emerg Med 1999; 33: 304-309.

25 Fahy JV, Kim KW, Liu J, et al. Prominent neutrophilic inflammation in sputum from subjects with asthma exacerbation. J Allergy Clin Immunol 1995; 95: 843-852.

26 in't Veen JC, Smits HH, Hiemstra PS, et al. Lung function and sputum characteristics of patients with severe asthma during an induced exacerbation by double-blind steroid withdrawal. Am J Respir Crit Care Med 1999; 160 : 93-99.

27 Pizzichini MM, Pizzichini E, Efthimiadis A, et al. Asthma and natural colds. Inflammatory indices in induced sputum: a feasibility study. Am J Respir Crit Care Med 1998; 158: 1178-1184.

28 Pizzichini MM, Pizzichini E, Clelland L, et al. Sputum in severe exacerbations of asthma: kinetics of inflammatory indices after prednisone treatment. Am J Respir Crit Care Med 1997; 155: 1501-1508.

29 Gibson PG, Dolovich J, Girgis-Gabardo A, et al. The inflammatory response in asthma exacerbation: changes in circulating eosinophils, basophils and their progenitors. Clin Exp Allergy 1990; 20: 661-668.

30 Baigelman W, Chodosh S, Pizzuto D, Cupples LA. Sputum and blood eosinophils during corticosteroid treatment of acute exacerbations of asthma. Am J Med 1983; 75: 929-936.

31 British Thoracic Society, Scottish Intercollegiate Guidelines Network. British Guideline on the Management of Asthma. Thorax 2003; 58: Suppl. 1, i1-i94.

32 Schuh S, Reisman J, Alshehri M, et al. A comparison of inhaled fluticasone and oral prednisone for children with severe acute asthma. $N$ Engl J Med 2000; 343: 689-694. 